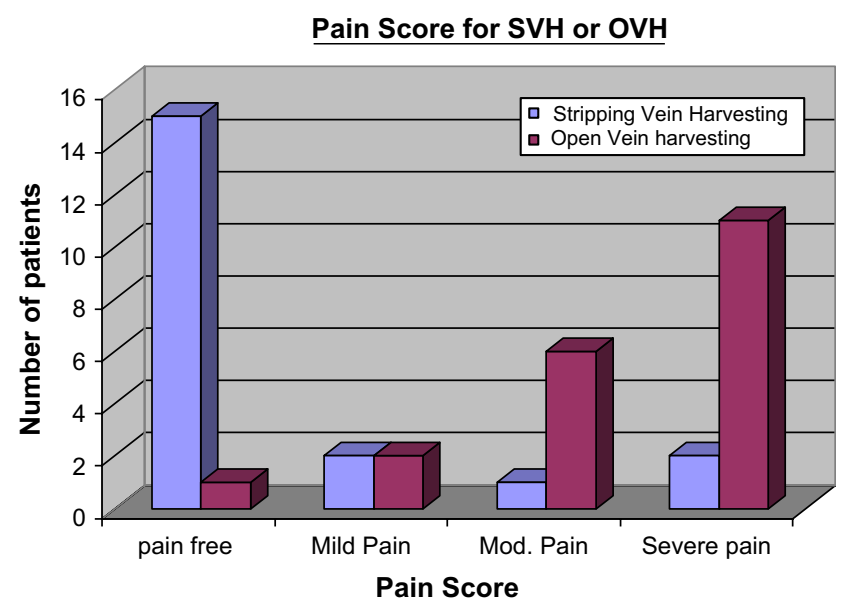

FIGURE 2. Pain score is much higher in the open vein harvesting technique group.

\section{DISCUSSION}

Harvesting the long saphenous vein by means of multiple small incisions and use of the mayo strippers is a well-recommended technique. ${ }^{2}$ We found that SVH was associated with less wound complications and wound pain, required shorter length of hospital stay, and did not add any cost to the procedure. It did not prolong the overall operative time nor compromise the vein quality both morphologically and functionally. We found that this maneuver facilitated vein dissection. It kept the vein very well hydrated and protected its integrity. It facilitated removal of the debris and clots generated after sliding the stripper. Further research is required to evaluate the potential benefits of this maneuver.

\section{References}

1. O'Regan DJ, Borland JA, Chester AH, Pennell DJ, Yacoub M, Pepper JR. Assessment of human long saphenous vein function with minimally invasive harvesting with the mayo stripper. Eur J Cardiothorac Surg. 1997;12:428-35.

2. Athanasiou T, Aziz O, Skapinakis P, Perunovic B, et al. Leg wound infection after coronary artery bypass grafting: a meta-analysis comparing minimally invasive versus conventional vein harvesting. Ann Thorac Surg. 2003;76:2141-6.

3. Horn EP, Schroeder F, Wilhelm S, et al. Wound infiltration and drain lavage with ropivacaine after major shoulder surgery. Anesth Analg. 1999;89:1461-6.

\title{
Electromagnetic interaction between an axial left ventricular assist device and an implantable cardioverter defibrillator
}

Farhad Bakhtiary, MD, Panagiotis Therapidis, MD, Mirela Scherer, MD, Omer Dzemali, MD, Anton Moritz, MD, PhD and Peter Kleine, MD, PhD, Frankfurt am Main, Germany

As the prevalence of advanced heart failure continues to increase, implantation of the left ventricular assist device (LVAD) has become an excellent bridge to cardiac transplantation, recovery, or other future alternative therapies. ${ }^{1,2}$ There is some evidence that LVAD therapy itself promotes new onset of ventricular arrhythmias in this patient group. ${ }^{1}$ Implantation of an implantable cardioverter-defibrillator (ICD) is one treatment choice. There is little information concerning device-device interaction between the LVAD and ICD. ${ }^{2}$

From the Department of Thoracic and Cardiovascular Surgery of Johann-WolfgangGoethe University, Frankfurt am Main, Germany.

Received for publication Oct 30, 2007; revisions received Jan 17, 2008; accepted for publication Feb 1, 2008.

Address for reprints: Farhad Bakhtiary, MD, Department of Thoracic and Cardiovascular Surgery, Johann-Wolfgang-Goethe University, Theodor Stern Kai 7, 60590

Frankfurt am Main, Germany (E-mail: farhad@bakhtiary.de).

J Thorac Cardiovasc Surg 2008;136:1380-1

0022-5223/\$34.00

Copyright (c) 2008 by The American Association for Thoracic Surgery doi:10.1016/j.jtcvs.2008.02.072
This report describes the case of a patient with intraoperative interaction between the LVAD and a newly implanted left-sided ICD, which was ultimately solved by right-sided reimplantation.

\section{CLINICAL SUMMARY}

A 54-year-old man was admitted to our institution in November 2006 with medically unresponsive end-stage heart failure resulting from dilated cardiomyopathy. He was in cardiogenic shock with a left ventricular ejection fraction of $15 \%$ and received extracorporeal membrane oxygenatation for 1 week. Implantation of a Thoratec HeartMate II LVAD (Thoratec Corporation, Pleasanton, Calif) with additional tricuspid valve annuloplasty was performed 10 days later. The LVAD inflow was positioned at the left ventricular apex, the outflow in the ascending aorta, and the device itself in the left upper part of the abdomen. His postoperative course was prolonged by respiratory insufficiency and intensive polyneuropathy. Finally, 100 days postoperatively, the patient was transferred to a neurologic and cardiac rehabilitation unit. After 6 weeks, the patient could 


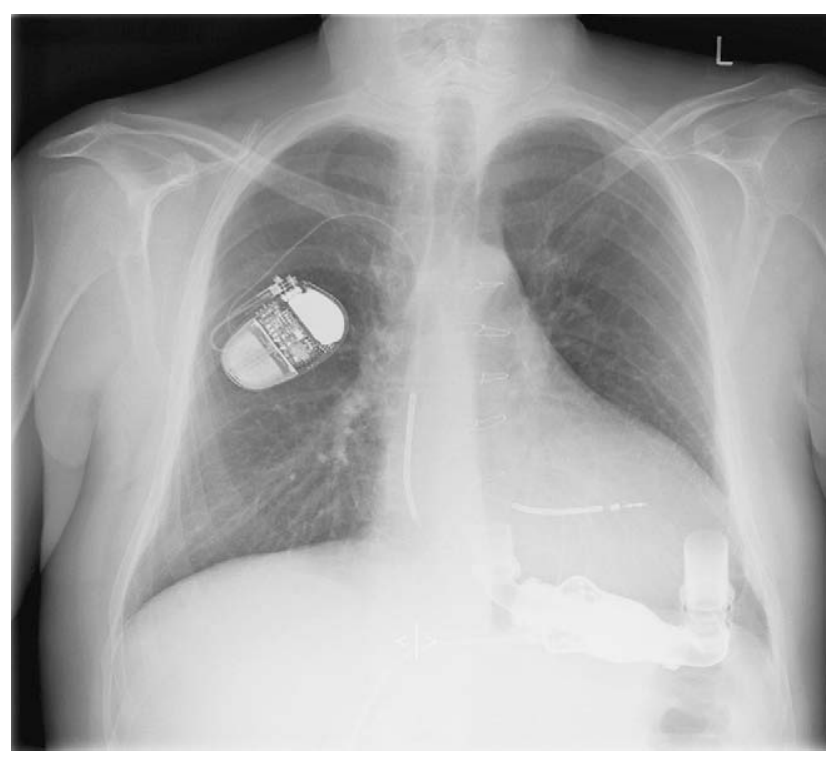

FIGURE 1. Chest $x$-ray film showing an axial left ventricular assist device, a single-chamber implantable cardioverter-defibrillator, and a transvenous screw-in lead.

be discharged from the rehabilitation center in good clinical condition.

Three months later, he was referred to our outpatient department for recurrent ventricular tachycardia. It was decided to implant a single-chamber ICD (Ela Ovatio VR; Sorin group, Saluggio, Italy). Transvenous lead implantation using a bipolar dual-coil lead with active fixation (Kentrox SL-S; Biotronik, Berlin, Germany) was uncomplicated (R-wave sensing, $8.5 \mathrm{mV}$, pacing threshold $0.75 \mathrm{mV}$, impedance $405 \Omega$ ). The generator was implanted into a left subpectoral pocket. After lead connection and replacement of the same generator in the pocket, sufficient telemetry between the ICD and the defibrillator programmer could not be established despite use of multiple programmers and programming head positions. The telemetry head always received electromagnetic signals even when placed far away from the generator. Because of inability to interrogate or reprogram the ICD in this location, we decided to reimplant both the lead and the generator in the same setting on the right pre-pectoral position (Figure 1). After implantation, ICD telemetry was stable and successful and ICD function undisturbed with successful termination of provoked ventricular fibrillation.

\section{CONCLUSION}

Some reports described the deleterious hemodynamic and clinical effects of ventricular arrhythmias in patients with LVADs, which may be caused by electrical instability owing to the underlying disease or mechanical disturbance by implantation of the apical inflow cannula. ${ }^{1}$ As LVAD and ICD therapy is being used concomitantly more often in this patient group with end-stage heart failure, device malfunction resulting from interaction has to be avoided. ${ }^{2,3}$ This report presents the case of a patient in whom intraoperative ICD interrogation was impossible owing to massive interference with the LVAD electromagnetic field. This problem could be solved by ICD displacement to the right pectoral side. The device-device interaction may be prevented by preoperative scanning of the thoracic wall using the ICD telemetry head, which should not display receipt of any electromechanical signals unless placed on top of the ICD generator. In cases of doubt, the generator should be implanted contralateral to the LVAD position, in the majority of cases at the right pectoral side rather than the left side.

\section{References}

1. Ziv O, Dizon J, Thosani A, Naka Y, Magnano AR, Garan H. Effects of left ventricular assist device therapy on ventricular arrhythmias. J Am Coll Cardiol. 2005;45: 1428-34.

2. Skinner JL, Bourge RC, Shepard RB, Epstein AE, Holman WL. Simultaneous use of an implanted defibrillator and ventricular assist device. Ann Thorac Surg. 1997; 64:1156-8.

3. Matthews JC, Betley D, Morady F, Pelosi F Jr. Adverse interaction between a left ventricular assist device and an implantable cardioverter defibrillator. J Cardiovasc Electrophysiol. 2007;18:1107-8. 